\title{
COVID-19 and Its Predicament on LGBT Communities in India - A Mini Review
}

\author{
Joshitha Sankam
}

Department of Public Health, Prasanna School of Public Health, Manipal, Karnataka, India

\begin{abstract}
The COVID-19 pandemic has impacted the lives of many people around the globe. The pandemic results in increased challenges and risks for LGBT communities making them more vulnerable to the outbreak. The lives of LGBT communities were not comfortable before the "new normal," and the pandemic has further caused a strain on their ways of life. This article reviews the impact and predicament of COVID 19 on the LGBT communities of India.
\end{abstract}

Key Words: COVID 19, LGBT Communities, healthcare, transgender, mental health, discrimination

\section{INTRODUCTION}

The COVID 19 pandemic is a new topic on the table all over the globe. There is a lot of ongoing research on COVID 19 and it is placed above all the ongoing issues. This new virus is a threat to everyone worldwide and the LGBT communities are also in its grasp. The LGBT communities were facing hardships long before the wrath of the pandemic. Access to quality healthcare and equality in healthcare remains an ordeal for these communities ${ }^{[1]}$. People's lives and livelihood were altered during the pandemic and its effect on the LGBT communities was more drastic. This paper reviews the impact of COVID 19 on India's Lesbian, gay, bisexual, trans (LGBT) communities.

\section{Overview of LGBT In India}

After a lot of havoc which began in 2009, which started with the decriminalization of homosexuality and again criminalization in 2013 and finally in
August 2017, India's LGBT communities were given the freedom to safely express their sexual orientation the Supreme Court. On $6^{\text {th }}$ September 2018, consensual gay sec was legalized by India's Supreme Court ${ }^{[2]}$. India's moral and social values differ from other countries, making it complicated to normalize the LGBT culture ${ }^{[3]}$. Even a year after the ruling for LGBT rights in India, the communities face challenges pertaining to same-sex marriage, jobs, education, healthcare and housing in the socially conservative country ${ }^{[5]}$. The challenges faced differing between the urban and rural LGBT communities as the rural communities find it challenging to find a partner and live in fear of being ostracized if they were to come out ${ }^{[5]}$. There are no official demographics for the LGBT communities in India. Still, the government of India gave a figure to the Supreme Court in 2012 that about 2.5 million gay people are recorded based on the individuals who have self-declared to the Ministry of Health [6].

\section{The predicament of COVID 19 on LGBT communities of India}

In the ongoing COVID 19 crisis, the

LGBT communities are considered particularly vulnerable to contract the virus due to various factors. Firstly, the LGBT communities experience higher rates of cancer and HIV, which makes the immune system weak and vulnerable. Along with this, the HIV persons undergoing treatment like antiretroviral therapy and other treatments are affected due to the lockdown measures, which resulted in a lack of 
transport facilities and health care facilities either not functioning or being filled up with COVID 19 cases ${ }^{[7]}$. Secondly, transgender adults are particularly at more risk as they are rated with poor health compared to others. According to National Centre for Transgender Equality (NCTE), more than one out of five transgender adults have one or more chronic conditions such as diabetes, asthma, or arthritis, increasing their vulnerability ${ }^{[8]}$. Transgender people (especially Hijra/Kinnar communities) have no daily income access as their traditional livelihoods are disrupted due to lockdown and social distancing measures ${ }^{[8]}$. Thirdly, the habit of smoking is considered to be more in LGBT people compared to nonLGBT and cisgender adults ${ }^{[10]}$. COVID 19 being a respiratory illness puts the LGBT communities at a higher risk and makes them more vulnerable. Fourthly, LGBT communities experience a lack of cultural competence and discrimination when they seek healthcare and health-related facilities, resulting in them avoiding or delaying seeing health care at times of emergencies [11]. The overloaded health systems can lead to the LGBT people being deprioritized for treatments like HIV testing, hormonal treatment and gender-affirming treatment for trans people. This discrimination of health care provision and access elevated the risk of LGBT people from COVID 19. Finally, there was an increased strain on mental health. The LGBT people who stayed with unsupportive families due to lockdown measures dealt with stress, anxiety, trauma, and jeopardizing their mental health status. Some of them have no place to self-isolate due to lockdown measures either because they were rejected by their families and had to face stigmatization regularly or due to their low economic status due to discrimination ${ }^{[11]}$. The LGBT elders were also affected as they had no one to take care of them and we're left alone amidst these protocols of selfsolation and lockdown. Suicides and attempts to commit suicides were seen increasing, as pointed out by media reports, due to increasing loneliness and depression among the communities and the inability to access psychiatric help ${ }^{[12]}$.

\section{DISCUSSION}

Based on the above factors, it is identified that the LGBT communities are particularly at risk and vulnerable to COVID 19 because of compromised immune systems of people living with HIV/AIDS, smoking habits, homeless persons, no proper access to healthcare services and healthcare discrimination. The mental health of the LGBT communities is also affected by people in lockdown with unsupportive family members, older adults who are left alone in self-isolation, people experiencing homelessness and unemployment, which caused financial strain leading to an increase in depression and anxiety disorders. Based on these factors, they were prone to the adverse impact of the COVID 19 pandemic. The hardships faced by these communities before the pandemic was not easy and now it has been made more complicated, both in terms of healthcare and their regular livelihood. During the time of the crisis, society's acceptance and adaptiveness are put to the test. The world is fighting the COVID 19 pandemic. The LGBT communities, especially in India, continue to struggle with discrimination and protocols of self-isolation and lockdowns imposed.

\section{CONCLUSION}

The COVID 19 pandemic has put a halt to our standard ways of life and we have to understand that the marginalized communities who were more vulnerable "then" are more susceptible "now." We have to promote helping LGBT communities cope with this ongoing crisis and remove the stigma because COVID 19 does not discriminate and is more at risk. A strategic plan has to be made to ensure safety and measures for the LGBT communities in India. This is the right time to empower the LGBT communities of India in terms of 
social security, physical, mental and sexual health.

\section{REFERENCES}

1. Masoodi A. Accessing healthcare still an ordeal for LGBTQ in India [Internet]. mint. 2021 [cited 23 February 2021]. Available from:

https://www.livemint.com/Politics/w6C5ws 5POJ7d10590mP6mJ/Accessinghealthcare-still-an-ordeal-for-LGBTQ-inIndia.html

2. Rajagopal K. SC decriminalizes homosexuality, says history owes LGBTQ community an apology [Internet]. The Hindu. The Hindu; 2018 [cited 2020Aug20]. Available from: https://www.thehindu.com/news/national/sc -de-criminalises-homosexuality-sayshistory-owes-lgbtq-community-anapology/article24881549.ece?homepage $=$ tru $\mathrm{e}$

3. LGBT history of India [Internet]. 2018 [cited 2020Aug22]. Available from: https://en.wikipedia.org/wiki/LGBT_history _of_India

4. Banerji A. One year after landmark ruling for LGBT+ rights in India, challenges persist [Internet]. Reuters. Thomson Reuters; 2019 [cited 2020Aug22]. Available from: https://www.reuters.com/article/usindia-lgbt/one-year-after-landmark-rulingfor-lgbt-rights-in-india-challenges-persistidUSKCN1VR256

5. Pandey V. What it means to be gay in rural India [Internet]. BBC News. BBC; 2018 [cited 2020Aug22]. Available from: https://www.bbc.com/news/world-asiaindia-45430953

6. India has $2.5 \mathrm{~m}$ gays, government tells supreme court [Internet]. BBC News. BBC; 2012 [cited 2020Aug22]. Available from: https://www.bbc.com/news/world-asiaindia-17363200
7. Eadens S. LGBTQ community may be 'particularly vulnerable' to coronavirus pandemic. Here's why. [Internet]. USA Today. Gannett Satellite Information Network; 2020 [cited 2020Aug22]. Available from: https://www.usatoday.com/story/news/natio n/2020/03/18/lgbtq-coronaviruscommunity-vulnerable-covid-19pandemic/2863813001/

8. Sebastian, S. (2020, April 01). COVID-19: What about the transgender community? Retrieved August 23, 2020, from https://www.downtoearth.org.in/news/gover nance/covid-19-what-about-the-transgendercommunity--70151

9. FICCI. IMPACT OF COVID -19 on LGBTIQ+ COMMUNITIES IN INDIA [Internet]. 2020 [cited 2020Aug22]. Available from: http://ficci.in/SEDocument/20500/ficcirecommendation-apr2-1.pdf

10. Banerjee D, Nair VS. "The Untold Side of COVID-19": Struggle and Perspectives of the Sexual Minorities. Journal of Psychosexual Health. 2020:2631831820939017.

11. Roy S. Plight of LGBT community during the Covid-19 pandemic [Internet]. NORTHEAST NOW. 2020 [cited 2020Aug22]. Available from: https://nenow.in/opinion/plight-of-lgbtcommunity-during-covid-19-pandemic.html

12. Chakraborty S. COVID-19 pandemic takes toll on mental health of sexual minorities [Internet]. Downtoearth.org.in. 2021 [cited 23 February 2021]. Available from: https://www.downtoearth.org.in/news/health /covid-19-pandemic-takes-toll-on-mentalhealth-of-sexual-minorities-71284

How to cite this article: Sankam J. COVID-19 and its predicament on LGBT communities in India - a mini review. International Journal of Research and Review. 2021; 8(3): 25-27. 